\title{
STUDI KESESUAIAN WISATA PANTAI NGLAMBOR SEBAGAI OBJEK REKREASI PANTAI DI KABUPATEN GUNUNGKIDUL
}

\author{
Study of Nglambor Beach Tourism Suitability as the Object of Beach Recreation at Gunungkidul Regency
}

\author{
Pintya Dwanita Ayu Pratesthi, Frida Purwanti*), Siti Rudiyanti
}

Program Studi Manajemen Sumberdaya Perairan, Departemen Sumberdaya Akuatik Fakultas Perikanan dan Ilmu Kelautan, Universitas Diponegoro

J1. Prof. Soedarto, SH, Tembalang, Semarang, Jawa Tengah - 50275, Telp/Fax, +6224 7474698

E-mail : rrpintya@yahoo.co.id

\begin{abstract}
ABSTRAK
Ekowisata adalah kegiatan wisata alam yang memanfaatkan lingkungan, memperhatikan unsur-unsur konservasi, ekonomi, edukasi dan pemberdayaan masyarakat setempat. Salah satu pantai yang termasuk dalam ekowisata adalah Pantai Nglambor yang terletak di Desa Purwodadi, Kecamatan Tepus, kabupaten Gunungkidul. Tujuan penelitian ini untuk mengetahui potensi dan perkembangan wisata Pantai Nglambor dan mengetahui nilai Indeks Kesesuaian Wisata (IKW) Pantai Nglambor serta kategorinya. Penelitian ini dilakukan pada bulan Januari-Juli 2016. Metode yang digunakan pada penelitian ini adalah metode penelitian kuantitatif menggunakan IKW dengan teknik purposive sampling dan metode deskriptif dengan teknik voluntary sampling untuk kuisioner 60 responden. Potensi wisata Pantai Nglambor ada pada kondisi fisik pantai yang unik dan indah, serta jenis kegiatan atau daya tarik wisatanya yaitu berenang dan snorkeling, sedangkan perkembangan wisata Pantai Nglambor dalam satu tahun sudah menjadi tujuan utama bagi pengunjung dan nilai untuk kepuasan serta keinginan untuk kembali berkunjung dari pengunjung adalah 95.1\%. Nilai IKW untuk Pantai Nglambor pada semua Stasiun saat surut (sore) dan saat pasang (pagi) adalah S1 atau Sangat Sesuai (Highly Suitable) dengan kisaran nilai sebesar 84.52\% hingga $90.48 \%$ kecuali pada Stasiun I saat pasang (pagi) termasuk kategori S2 atau Sesuai (Suitable) dengan nilai sebesar $78.57 \%$.
\end{abstract}

Kata kunci: Kesesuaian Wisata; Pantai Nglambor; Gunungkidul

\begin{abstract}
Ecotourism is nature tourism activities that utilize environment, which concern on the elements of conservation, economic, education and also empowering local communities. One of the beaches that can be an ecotourism destination is Nglambor Beach located in Purwodadi village, Tepus sub-district, Gunungkidul regency. The purpose of this study are to know the potential and development of tourism in Nglambor Beach and to determine the value of Tourism Suitability Index of Nglambor Beach and it's categories. This study was conducted in January to July, 2016. The method used in this research were quantitative method using Tourism Suitability Index with purposive sampling technique and descriptive method by distributing questionnaires using voluntary sampling technique to 60 respondents. The potential of $\mathrm{Nglambor} \mathrm{Beach} \mathrm{is} \mathrm{in} \mathrm{the} \mathrm{physical} \mathrm{condition} \mathrm{of} \mathrm{the} \mathrm{unique}$ and beautiful beach, as well as the type of tourism activities or attraction i.e swimming and snorkeling, while the development of Nglambor beach whitin a year has become a main tourism destination with the value of satisfaction and the desire to re-visit is 95.1\%. Value of Tourism Suitability Index of Nglambor Beach at all stations at low tide (evening) and the high tide (morning) are S1 or Highly Suitable with a value range of $84.52 \%$ to $90.48 \%$, except at Station I at the high tide (morning) is S2 or Suitable with a value of $78.57 \%$.
\end{abstract}

Keywords: Ecotourism Suitability; Nglambor Beach; Gunungkidul

*) Penulis penanggungjawab

\section{PENDAHULUAN}

Meningkatnya kesadaran masyarakat mengenai lingkungan telah mendorong lahirnya wisatawan peduli lingkungan yang memiliki motivasi untuk menyentuh alam lingkungan yang asli, utuh dan tenang, untuk memperoleh pengalaman-pengalaman baru serta menikmati panorama alam. Perubahan persepsi masyarakat dari menggunakan wisata massal menjadi ekowisata meningkat berdasarkan beberapa karakteristik ekowisata. Kegiatan wisata yang berkaitan dengan konservasi lingkungan.

${ }^{\circledR}$ Copyright by Management of Aquatic Resources (MAQUARES) 
Ekowisata tidak hanya menyiapkan sekedar atraksi wisata, akan tetapi menawarkan pula peluang untuk menghargai lingkungan secara berkesinambungan. Ekowisata memiliki tanggung jawab ekonomi dalam pelestarian lingkungan yang dikunjungi dan dinikmati wisatawan melalui berbagai kegiatan yang dapat menghasilkan pendapatan yang dapat dikembalikan bagi kepentingan konservasi lingkungan dan kunjungan wisatawan untuk pengembangan lingkungan yang berkelanjutan yang dapat dinikmati oleh para pecinta lingkungan lainnya.

Ekowisata biasa diterjemahkan dengan wisata alam adalah kegiatan wisata yang memanfaatkan jasa lingkungan, baik itu keindahan dan keunikan alamnya ataupun masyarakat (budayanya, cara hidupnya, struktur sosialnya) dengan mengemukakan unsur-unsur konservasi, edukasi dan pemberdayaan masyarakat setempat (Fandeli, 2000).

Kabupaten Gunungkidul adalah salah satu kabupaten di Daerah Istimewa Yogyakarta, Indonesia. Pusat pemerintahan berada di Kecamatan Wonosari. Kabupaten Gunungkidul memiliki banyak potensi pariwisata, salah satunya adalah ekowisata air wisata pantai. Salah satu daerah yang memiliki potensi ekowisata air yang cukup baik adalah Pantai Nglambor.

Pantai Nglambor Gunungkidul adalah pantai yang dikelilingi oleh bukit kapur dan di depan pantai dihiasi dengan tiga bukit karang bernama Pulau Nglambor, Pulau Purba, dan Pulau Kuntul yang berfungsi sebagai pemecah ombak dari Samudra Hindia yang terkenal akan ombaknya yang besar. Pantai Nglambor Gunungkidul memiliki beberapa kelebihan atraksi seperti wisata pantai, wisata snorkeling, wisata bukit, dan wisata kuliner.

Wisata Bahari dan wisata pantai (marine tourism) adalah suatu kunjungan ke objek wisata, khususnya untuk menyaksikan keindahan lautan, menyelam dengan perlengkapan selam lengkap, kegiatan wisata ini juga ditunjang oleh sarana dan prasarana untuk berenang, memancing, menyelam, dan olahraga air lainnya, termasuk sarana dan prasarana akomodasi, tersedianya makanan dan minuman (Yoeti, 1996).

Analisis kesesuaian wisata merupakan suatu kajian untuk menilai kecocokan dari suatu aktivitas yang dilakukan di suatu kawasan sesuai dengan potensi sumberdaya dan peruntukannya dengan menggunakan berbagai variabel. Studi kesesuaian wisata beserta kegiatannya pada kawasan pesisir khususnya pantai menjadi penting untuk dipelajari agar memiliki dampak baik bagi pantai tersebut yang berujung pada sesuai atau tidak sesuaikah pantai ini menjadi objek wisata alam yang berbasis pada pemanfaatan lingkungan berkelanjutan. Dalam mempelajari studi ini dibutuhkan pengambilan data parameter dengan variabel-variabel tertentu yang hasilnya dapat menunjukkan kelas atau kategori dari Pantai Nglambor ini.

Tujuan dari penelitian ini adalah untuk mengetahui potensi dan perkembangan wisata Pantai Nglambor dan mengetahui nilai Indeks Kesesuaian Wisata Pantai Nglambor serta kategorinya. Penelitian ini dilaksanakan mulai dari bulan Januari hingga Juli 2016 di Pantai Nglambor, Kabupaten Gunungkidul.

\section{MATERI DAN METODE PENELITIAN}

\section{A. MATERI PENELITIAN}

Materi yang diamati pada penelitian ini adalah potensi dan perkembangan wisata Pantai Nglambor serta kondisi bio-fisik kesesuaian wisata Pantai Nglambor, Gunungkidul. Alat yang digunakan dalam pelaksanaan penelitian meliputi; alat tulis, kertas, secchi disk modifikasi, rollmeter, bola arus, Global Positioning System (GPS), kalkulator scientific, dan kuisioner potensi dan perkembangan wisata Pantai Nglambor.

\section{B. METODE PENELITIAN}

Metode yang digunakan pada penelitian ini adalah metode penelitian kuantitatif menggunakan Indeks Kesesuaian Wisata (IKW) dengan teknik purposive sampling dan metode deskriptif dengan teknik voluntary sampling untuk kuisioner sebanyak 60 responden. Menurut Emzir (2012), metode penelitian kuantitatif adalah metode yang secara primer menggunakan paradigma postpositivist dalam mengembangkan ilmu pengetahuan. Contohnya seperti pemikiran tentang sebab akibat, reduksi kepada variabel, hipotesis, dan pertanyaan spesifik, menggunakan pengukuran dan observasi, serta pengujian teori. Menggunakan strategi seperti eksperimen dan survei yang memerlukan data statistik.

\section{Pengambilan sampel}

Metode pengambilan sampel menggunakan teknik purposive sampling, yaitu pengambilan sampel secara sengaja, sesuai dengan persyaratan sampel yang diperlukan dengan asumsi bahwa sampel yang diambil dapat mewakili populasi dari lokasi penelitian dan teknik voluntary sampling adalah teknik yang dilakukan jika satuan sampling dikumpulkan atas dasar sukarela. Teknik pengambilan sampel ini banyak diterapkan pada penelitian pasar dan penelitian pengumpulan pendapat (opinion) atau jejak pendapat.

Pada penelitian ini penerapan metodelogi terutama diarahkan pada pemilihan stasiun yang masih terjangkau untuk digunakan kegiatan berwisata. Pengambilan data sekunder berguna untuk mendukung data primer, data sekunder tersebut yaitu data Rincian Pengunjung Tempat Rekreasi dan Olahraga Kabupaten Gunungkidul Tahun 2015. Pengukuran parameter kesesuaian wisata pantai dilakukan di setiap titik pengamatan dengan pengulangan sebanyak dua kali, satu kali pada saat surut (pagi hari) dan satu kali pada saat surut (sore hari). 


\section{Penentuan lokasi sampling}

Stasiun pengambilan sampel dibagi menjadi tiga titik, yaitu Stasiun I terletak di sebelah Barat Pantai Nglambor, Stasiun II terletak diantara Stasiun I dan Stasiun III, dan Stasiun III terletak di sebelah Timur Pantai Nglambor. Teknik pengambilan sampel pada penelitian ini menggunakan teknik purposive sampling. Menurut Sugiyono (2009), metode purposive sampling merupakan teknik pengambilan sampel sumber data dengan pertimbangan tertentu yang dapat mewakili dari lokasi penelitian. penentuan stasiun dilakukan secara horizontal (mendatar) dimana dari masing-masing stasiun kemudian ditarik garis tegak lurus dari bibir pantai menuju laut kurang lebih 15 meter. Hal ini dilakukan berdasarkan pertimbangan bahwa mayoritas pengunjung lebih memilih untuk melakukan kegiatan wisata yang jaraknya terjangkau atau masih dekat dengan bibir pantai, dengan demikian dapat mewakili informasi yang dibutuhkan untuk penelitian (Yutishar, 2012).

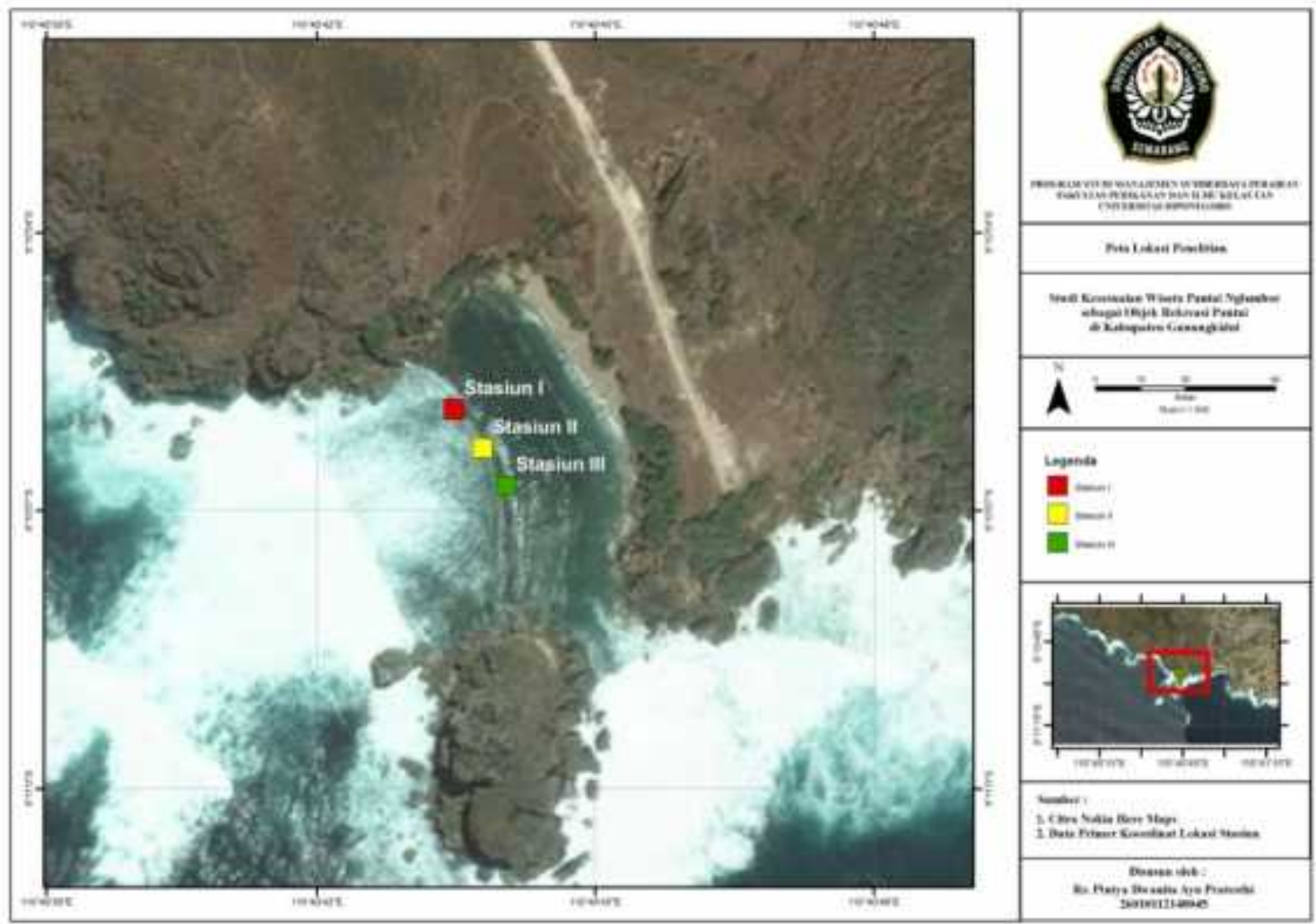

Gambar 1. Peta Lokasi Penelitian

\section{Pelaksanaan sampling}

Lokasi sampling dipilih berdasarkan stasiun yang masih terjangkau untuk dilakukan kegiatan berwisata di Pantai Nglambor. Lokasi penelitian (Gambar 1) dibagi atas tiga stasiun, dengan menentukan titik koordinat pada masing-masing stasiun dengan cara menarik panjang $15 \mathrm{~m}$ dari bibir pantai ke arah laut sehingga diperoleh titik koordinat pada masing-masing stasiun yaitu sebagai berikut, Stasiun I dengan titik koordinat LS $08^{\circ} 10^{\prime} 55.91$ " \& BT 110 40'43.47”, Stasiun II dengan titik koordinat LS 08 $10^{\prime} 56.33^{\prime \prime}$ \& BT 110 40'43.78”, dan Stasiun III dengan titik koordinat LS $08^{\circ} 10^{\prime} 56.73^{\prime \prime}$ \& BT $110^{\circ} 40^{\prime} 44.03^{\prime \prime}$. Masing-masing stasiun diambil sampel pada saat surut (sore) dan pasang (pagi).

\section{Indeks Kesesuaian Wisata}

Pengambilan data primer kesesuaian wisata dilakukan pada saat surut (sore) dan saat pasang (pagi). Pertimbangan pengambilan data ini karena ingin mencari tahu apakah ada perbedaan nilai Indeks Kesesuaian Wisata (IKW) dan kategorinya pada tiap stasiun di saat surut (sore) maupun saat pasang (pagi).

Analisis kesesuaian wisata yang digunakan dalam penelitian ini yaitu mengacu pada variabel dan rumus kesesuaian wisata pantai menurut Yulianda (2007).

Data primer kedalaman pantai diambil menggunakan tongkat berskala atau disebut juga dengan secchi disk modifikasi. Secchi disk modifikasi tersebut dimasukkan ke dalam perairan yang menjadi titik sampling pengambilan data, nilai yang ditunjukkan pada secchi disk modifikasi merupakan nilai kedalaman.

Tipe pantai diamati secara pengamatan visual, yaitu dengan mengamati jenis dan warna pasirnya lalu dicocokkan dengan kriteria kesesuaian wisata yang ada.

Pengukuran lebar pantai dilakukan menggunakan rollmeter, yaitu diukur jarak antara vegetasi terakhir yang ada di pantai dengan batas pasang tertinggi lalu dicocokkan dengan kriteria kesesuaian wisata yang ada. 
Material dasar perairan sangat menentukan kecerahan perairan. Daerah di sekitar pantai dengan substrat pasir merupakan lokasi yang sangat sesuai untuk wisata pantai. Toleransi diberikan pada substrat pasir berkarang atau karang berpasir dengan hancuran karang yang relatif lebih sedikit dibandingkan dengan karangnya maupun pasir berlumpur. Substrat lumpur maupun karang merupakan lokasi yang kurang sesuai untuk kegiatan berenang dan bermain air

Kecepatan arus diukur menggunakan bola arus, yaitu dengan menetapkan jarak tempuh bola arus kemudian diukur waktu tempuh bola arus tersebut. Kecepatan arus dapat diketahui menggunakan rumus sebagai berikut: Kecepatan arus $=$ jarak $(\mathrm{m}) /$ waktu (detik).

Kemiringan pantai berkaitan dengan berbagai aktivitas yang dapat dilakukan di pantai. Wisatawan sebagian besar menyukai pantai yang landai karena lebih mudah untuk melakukan berbagai aktivitas. Kemiringan pantai yang $\leq 10^{\circ}$ dianggap paling sesuai untuk wisata pantai, sedangkan kemiringan pantai yang lebih dari $45^{\circ}$ dianggap tidak sesuai untuk wisata pantai karena dianggap curam. Menurut Lestari (2013), pengukuran kemiringan pantai dilakukan menggunakan rollmeter dan tongkat berukuran 2 meter. Langkah pertama, kayu berukuran 2 meter diletakkan secara horizontal di atas pasir dan dilekatkan tepat pada batas pantai teratas. Setelah dipastikan horizontal, di hitung ketinggian tongkat tersebut dengan rollmeter. Sehingga dapat diketahui kemiringan pantai tersebut dengan cara menghitung sudut yang dibentuk antara garis horizontal dan vertikal yang didapatkan. Pengukuran ini dilakukan dari batas pantai teratas (Gambar 2).

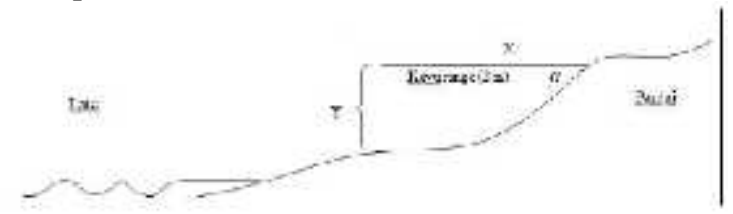

Gambar 2. Pengukuran Kemiringan Pantai

Kemiringan pantai dapat diperoleh dengan rumus:

$$
\tilde{n}=\arctan \frac{\mathrm{y}}{\mathrm{x}}
$$

Keterangan :

$\alpha=$ Sudut yang dibentuk $\left(^{\circ}\right)$

$\mathrm{Y}=$ Jarak antara garis tegak lurus yang dibentuk oleh kayu horizontal dengan permukaan pasir di bawahnya.

$\mathrm{X}=$ Panjang kayu $(2 \mathrm{~m})$

Pengukuran kecerahan perairan adalah berjarak 15 meter ke arah laut dari garis/bibir pantai atau stasiun yang dianggap aman untuk kegiatan wisata pantai. Pengukuran kecerahan dilakukan menggunakan secchi disk modifikasi kemudian diturunkan perlahan ke dalam perairan pada lokasi pengamatan. Nilai kecerahan perairan adalah rata-rata dari kedalaman secchi disk tidak terlihat dan kedalaman secchi disk yang sudah terlihat kembali.

Pengamatan penutupan lahan diperlukan untuk mengetahui kondisi fisik pantai dari keadaan sebenarnya di lapangan. Pengamatan ini dilakukan dengan melihat proses pertumbuhan kondisi pantai secara alamiah atau buatan manusia.

Pada penelitian ini, mengetahui biota yang berbahaya yaitu dengan mengamati biota-biota yang ada di pantai Nglambor lalu menggolongkannya apakah biota tersebut berbahaya bagi manusia atau tidak. Pengambilan data dapat diketahui melalui informasi dari wawancara dengan masyarakat sekitar. Bulu babi dan ikan pari menjadi indikator biota berbahaya karena kedua biota laut ini memiliki duri yang berbahaya bagi manusia (Juliana, 2013).

Langkah selanjutnya adalah menilai jarak ketersediaan air tawar di lokasi penelitian. Data ini didapatkan secara visual dan juga pengukuran, yaitu dengan mengamati sumber air tawar yang terdekat dari pantai yang digunakan oleh pengelola untuk menjadi sumber air bersih. Kemudian, jarak antara pantai dengan sumber air diukur.

Penilaian kesesuaian wisata pantai dilakukan dengan melakukan pengamatan dan pengukuran langsung di lapangan. Menurut Yulianda (2007), bahwa kesesuaian wisata pantai dapat direpresentasikan dalam bentuk Indeks Kesesuaian Wisata (IKW). Skala yang digunakan untuk mengisi kolom dalam menentukan tiap bobot ada 3, yaitu:

1. Bobot 5 (lima) : bahwa unsur parameter ini sangat diperlukan atau parameter kunci;

2. Bobot 3 (tiga) : dimana unsur parameter ini diperlukan atau cukup penting;

3. Bobot 1 (satu) : dimana unsur parameter ini dalam penilaian tidak begitu diperlukan atau kurang penting, yang artinya tanpa adanya parameter ini kegiatan wisata masih bisa berjalan.

Pemberian skor berdasarkan kualitas setiap parameter kesesuaian selama proses pengambilan data di lapangan. Kriteria untuk masing-masing skor adalah sebagai berikut:

a. Pemberian skor 3 : Kondisi parameter yang baik

b. Pemberian skor 2 : Kondisi parameter memiliki kualitas cukup baik

(C) Copyright by Management of Aquatic Resources (MAQUARES) 
c. Pemberian skor 1 : Kondisi parameter memiliki kondisi yang buruk

Setelah menentukan bobot dan skor, maka nilai Indeks Kesesuaian Wisata (IKW) dihitung berdasarkan total perkalian bobot dan skor semua parameter berdasarkan rumus menurut Yulianda (2007) yang digunakan untuk kesesuaian wisata pantai dan untuk mengetahui nilai kesesuaiannya, berikut adalah rumusannya:

$$
\text { IKW } \Sigma\left(\frac{\mathrm{Ni}}{\mathrm{N} \operatorname{mix}}\right) \times 100 \%
$$

Keterangan:

IKW :Indeks kesesuaian wisata

$\mathrm{Ni} \quad$ : Nilai parameter ke-i (Bobot x Skor)

Nmaks : Nilai maksimum dari kategori wisata

Keterangan : Jumlah $=($ Skor $\mathrm{x}$ Bobot $)$ dimana nilai maksimum $=84$

S1 $=$ Sangat Sesuai $(83-100 \%)$

$\mathrm{S} 2=$ Sesuai $(50-<83 \%)$

S3 $=$ Sesuai Bersyarat $(17-<50 \%)$

$\mathrm{N}=$ Tidak Sesuai $(<17 \%)$

\section{Kuisioner}

Setelah melakukan pengambilan data primer parameter kesesuaian wisata dilanjutkan dengan mengambil data kuisioner. Metode yang digunakan untuk analisis data adalah metode deskriptif. Teknik sampling kuisioner yang digunakan pada penelitian ini adalah sampling sukarela atau disebut juga dengan Voluntary Sampling. Kriteria responden yang dipilih ialah memiliki profil sebagai pengunjung, masyarakat desa, dan pengguna lain. Memiliki jenis kelamin (laki-laki atau perempuan), memiliki usia dengan kisaran 15-45 tahun, memiliki pendidikan mulai dari tingkat SD hingga tamat universitas. Bagi pengunjung, responden dipilih secara acak, sedangkan bagi masyarakat desa dipilih sesuai dengan profesi utama dan profesi tambahannya.

\section{HASIL PEMBAHASAN}

\section{Keadaan Umum Lokasi Penelitian}

Pantai Nglambor terletak di desa Purwodadi, Kecamatan Tepus, Kabupaten Gunungkidul. Kabupaten Gunungkidul adalah salah satu kabupaten di Daerah Istimewa Yogyakarta, Indonesia. Pusat pemerintahan berada di Kecamatan Wonosari memiliki luas $1.485,36 \mathrm{~km}^{2}$ atau sekitar $46,63 \%$ dari luas wilayah Daerah Istimewa Yogyakarta. Terletak pada koordinat $110^{\circ} 21^{\prime}-110^{\circ} 50^{\prime}$ BT dan $7^{\circ} 46^{\prime}-8^{\circ} 09^{\prime}$ LS. Sebagian besar wilayah kabupaten ini berupa perbukitan dan pegunungan kapur.

\section{Persepsi terhadap Potensi dan Perkembangan Wisata Pantai Nglambor}

Hasil yang didapatkan dari persepsi daya tarik wisata disajikan dalam Tabel 1 di bawah ini :

Tabel 1. Persepsi Daya Tarik Wisata

\begin{tabular}{|c|c|c|c|c|c|c|c|c|}
\hline No. & $\begin{array}{c}\text { Daya Tarik } \\
\text { Wisata }\end{array}$ & TM & $\mathbf{K M}$ & $\mathbf{C M}$ & $\mathbf{M}$ & SM & $\begin{array}{c}\text { Jumlah } \\
\text { Responden }\end{array}$ & $\begin{array}{c}\text { Persentase } \\
(\%)\end{array}$ \\
\hline 1. & $\begin{array}{l}\text { Pemandangan } \\
\text { alam }\end{array}$ & 2 & 1 & 6 & 15 & 6 & 30 & \\
\hline 2. & $\begin{array}{l}\text { Rekreasi } \\
\text { berenang }\end{array}$ & 1 & 2 & 10 & 13 & 4 & 30 & \\
\hline 3. & $\begin{array}{l}\text { Rekreasi } \\
\text { snorkeling }\end{array}$ & 0 & 1 & 8 & 15 & 6 & 30 & \\
\hline 4. & Rekreasi bukit & 2 & 1 & 3 & 17 & 7 & 30 & \\
\hline 5. & Kuliner & 3 & 6 & 15 & 6 & 0 & 30 & \\
\hline & Total & 8 & 11 & 42 & 66 & 23 & & \\
\hline \multicolumn{2}{|c|}{ Persentase (\%) } & 5.3 & 7.3 & 28 & 44 & 15.4 & & 100 \\
\hline
\end{tabular}

Keterangan:

$\begin{array}{ll}\text { TM } & \text { : Tidak Menarik } \\ \text { KM } & \text { : Kurang Menarik } \\ \text { CM } & \text { : Cukup Menarik } \\ \text { M } & \text { : Menarik } \\ \text { SM } & \text { : Sangat Menarik }\end{array}$
berikut:

Potensi dan Perkembangan Wisata Pantai Nglambor berdasarkan hasil yang telah didapatkan adalah sebagai 
Beberapa kegiatan wisata yang terdapat di Pantai Nglambor adalah pemandangan alam, rekreasi berenang, rekreasi snorkeling, rekreasi bukit, dan kulinernya. Beberapa kriteria ini tergabung dalam satu variabel yaitu jenis kegiatan/daya tarik wisata. Berdasarkan hasil yang didapatkan dari data penelitian, sebagian besar responden memilih kategori Menarik dengan nilai 44\% untuk persepsi daya tarik wisata.

Hasil dari persepsi terhadap potensi wisata Pantai Nglambor disajikan dalam Tabel 2 di bawah ini : Tabel 2. Persepsi terhadap Potensi Wisata

\begin{tabular}{|c|c|c|c|c|c|c|c|c|}
\hline No. & $\begin{array}{c}\text { Jenis Potensi } \\
\text { Wisata }\end{array}$ & TB & KB & CB & B & SB & $\begin{array}{c}\text { Jumlah } \\
\text { Responden }\end{array}$ & $\begin{array}{c}\text { Persentase } \\
(\%)\end{array}$ \\
\hline 1. & $\begin{array}{l}\text { Kondisi fisik } \\
\text { pantai }\end{array}$ & 0 & 1 & 12 & 13 & 4 & 30 & \\
\hline 2. & $\begin{array}{l}\text { Daya Tarik } \\
\text { Wisata }\end{array}$ & 0 & 1 & 15 & 12 & 2 & 30 & \\
\hline 3. & $\begin{array}{l}\text { Sarana dan } \\
\text { prasarana }\end{array}$ & 0 & 4 & 11 & 14 & 1 & 30 & \\
\hline 4. & Aksesibilitas & 0 & 3 & 15 & 11 & 1 & 30 & \\
\hline 5. & Fasilitas & 1 & 4 & 11 & 13 & 1 & 30 & \\
\hline & Total & 1 & 13 & 64 & 63 & 9 & & \\
\hline \multicolumn{2}{|c|}{ Persentase (\%) } & 0.6 & 8.7 & 42.7 & 42.0 & 6.0 & & 100 \\
\hline
\end{tabular}

\section{Keterangan:}

$\begin{array}{ll}\text { TB } & \text { : Tidak Baik } \\ \text { KB } & \text { : Kurang Baik } \\ \text { CB } & \text { : Cukup Baik } \\ \text { B } & \text { : Baik } \\ \text { SB } & \text { : Sangat Baik }\end{array}$

Variabel-variabel lainnya yang menjadi potensi wisata Pantai Nglambor adalah kondisi fisik pantai, jenis kegiatan, sarana dan prasarana, aksesibilitas, dan fasilitas. Persepsi potensi wisata oleh responden didapatkan nilai sebesar 0.6\% untuk kategori Tidak Baik, 8.7\% untuk kategori Kurang Baik, $42.7 \%$ untuk kategori Cukup Baik, 42.0\% untuk kategori Baik, dan 6.0\% untuk kategori Sangat Baik. Berdasarkan hasil yang didapatkan dari data penelitian, sebagian besar responden memilih kategori Cukup Baik dengan nilai $42.7 \%$ untuk persepsi potensi wisata.

Pantai Nglambor memiliki potensi yang besar untuk dimanfaatkan sebagai kawasan wisata pantai. Berdasarkan hasil yang didapatkan bahwa kondisi fisik pantai dan jenis kegiatan/daya tarik wisata dipilih oleh responden sebagai faktor yang membuat Pantai Nglambor menjadi layak untuk dikunjungi. Kondisi fisik pantai yang unik memiliki tebing terjal, bukit karst, pengalaman berwisata yang tidak seperti biasanya, indah, bersih, dan berpasir putih, menjadikan Pantai Nglambor sebagai destinasi wisatawan. Sedangkan untuk jenis kegiatan atau daya tarik wisata, Pantai Nglambor memiliki beberapa kegiatan yang dapat dilakukan di pantai tersebut.

Rekreasi berenang, rekreasi snorkeling, rekreasi bukit dimana terdapat bukit karst yang terletak dekat dari Pantai Nglambor, dari bukit tersebut wisatawan dapat melihat keindahan alam dan Pantai Nglambor dari atas, serta melihat tiga pulau di atas air dari bukit ini. Jika pengunjung tidak ingin melakukan aktifitas atau berkegiatan yang berhubungan dengan air, maka pilihan rekreasi ini bisa jadi salah satu alternatif. Beberapa opsi ini dapat memberi nilai tambah untuk Pantai Nglambor sendiri. Menurut Sunarto (1991), wisata pantai merupakan kegiatan wisata yang mengutamakan sumberdaya pantai dan budaya masyarakatnya seperti rekreasi, olahraga, dan menikmati pemandangan alam. Pantai yang digunakan sebagai wisata adalah pantai yang memiliki keindahan alam, selain itu juga memiliki daya tarik potensial seperti pasir putih, ombak yang relatif tenang, pantai dengan tebing terjal, pantai dengan pohon-pohon khas yang rindang, dan pantai dengan bangunan nilai sejarah atau budaya.

Hasil dari persepsi terhadap perkembangan wisata Pantai Nglambor disajikan dalam Tabel 3 di bawah ini : Tabel 3. Potensi terhadap Perkembangan Wisata

\begin{tabular}{|c|c|c|c|c|c|c|c|c|}
\hline No. & $\begin{array}{c}\text { Jenis } \\
\text { Perkembangan } \\
\text { Wisata }\end{array}$ & TB & KB & CB & B & SB & $\begin{array}{c}\text { Jumlah } \\
\text { Responden }\end{array}$ & $\begin{array}{c}\text { Persentase } \\
(\%)\end{array}$ \\
\hline 1. & $\begin{array}{l}\text { Kepuasan } \\
\text { wisatawan }\end{array}$ & 1 & 0 & 10 & 14 & 5 & 30 & \\
\hline 2. & $\begin{array}{l}\text { Keinginan untuk } \\
\text { kembali } \\
\text { berkunjung }\end{array}$ & 1 & 1 & 9 & 14 & 5 & 30 & \\
\hline & Total & 2 & 1 & 19 & 28 & 10 & 60 & \\
\hline & sentase (\%) & 3.3 & 1.6 & 31.7 & 46.7 & 16.7 & & 100 \\
\hline
\end{tabular}


Keterangan:

$\begin{array}{ll}\text { TB } & \text { : Tidak Baik } \\ \text { KB } & \text { : Kurang Baik } \\ \text { CB } & \text { : Cukup Baik } \\ \text { B } & \text { : Baik } \\ \text { SB } & \text { : Sangat Baik }\end{array}$

Perkembangan wisata yang terjadi di Pantai Nglambor adalah pantai ini sudah menjadi tujuan utama bagi para wisatawan walaupun effort atau pengorbanan yang lebih harus dikeluarkan contohnya jarak tempuh yang jauh dan akses yang masih sederhana tidak membuat wisatawan beranjak dari pantai ini. Selain itu, umur pantai yang terbilang masih muda yaitu satu tahun namun antusias pengunjung tidak surut untuk menikmati keindahan alam dan rekreasi snorkeling.

Berbagai variabel yang baik membuat persepsi responden terhadap potensi dan perkembangan Pantai Nglambor memiliki nilai yang tinggi dan berujung pada nilai kepuasan serta keinginan untuk kembali berkunjung. Berdasarkan hasil Tabel 3 didapatkan nilai persepsi terhadap perkembangan wisata di Pantai Nglambor sebesar 3.3\% (tidak baik), 1.6\% (kurang baik), 31.7\% (cukup baik), 46.7\% (baik), dan 16.7\% (sangat baik). Nilai tersebut menunjukkan bahwa sebagian besar pengunjung merasa puas dan ingin kembali berkunjung ke Pantai Nglambor. Menurut Koswara (2005), preferensi dan motivasi wisatawan yang berkembang, serta kecenderungan pengunjung untuk kembali ke alam menyebabkan pengembangan daya tarik wisata berbasis alam menjadi potensial.

\section{Kesesuaian Wisata Pantai Nglambor}

Hasil dari nilai Indeks Kesesuaian Wisata Pantai Nglambor saat Surut (Sore Hari) disajikan dalam Tabel 4 di bawah ini :

Tabel 4. Indeks Kesesuaian Wisata Pantai Nglambor saat Surut (Sore Hari)

\begin{tabular}{|c|c|c|c|c|c|c|c|c|c|c|}
\hline No: & Variabel & $\begin{array}{c}\text { Hesil } \\
\text { Stacinn T }\end{array}$ & Kategcri & $\begin{array}{c}\text { Skor } \\
\text { Rategori }\end{array}$ & $\begin{array}{l}\text { Hasil } \\
\text { Stasinu II }\end{array}$ & Kategori & $\begin{array}{c}\text { Sker } \\
\text { Kategani }\end{array}$ & $\begin{array}{c}\text { Bssil } \\
\text { 5tasiun } \\
\text { III }\end{array}$ & Kategoni & $\begin{array}{c}\text { Skor } \\
\text { Kutezmi }\end{array}$ \\
\hline 1. & $\begin{array}{l}\text { Keil.Lmarn peatir } \\
\text { (m) }\end{array}$ & 0.75 & SL & 15 & 1.05 & $\$ 1$ & 15 & 1.10 & S1 & 15 \\
\hline 7 & Tipe pantai & $\begin{array}{l}\text { Рaxiт mutih, } \\
\text { Sulkit k.ar=sy }\end{array}$ & S) & in & $\begin{array}{l}\text { Pasir puifh. } \\
\text { Sesilkit } \\
\text { tarang }\end{array}$ & $\$ 2$ & 10 & $\begin{array}{l}\text { Pasir } \\
\text { putil }\end{array}$ & Si & 15 \\
\hline 3. & LCosp panrai (m) & $12 \%$ & 82 & 10 & 13.8 & $S 2$ & 10 & 10.0 & 82 & 10 \\
\hline 4. & Marcrial dasar peraiysn & $\begin{array}{l}\text { Karaug } \\
\text { berpasir }\end{array}$ & 82 & 6 & $\begin{array}{l}\text { Raruig } \\
\text { berpasiz. }\end{array}$ & \$2 & 8 & $\begin{array}{l}\text { Karane } \\
\text { berpagir }\end{array}$ & 82 & 6 \\
\hline$\therefore$. & Kecepatan aus (us/s). & C.19. & SL. & 9 & $0.1 !$ & SI & 3 & C.14 & Si: & 9 \\
\hline 6. & Kunribsat pantai $(\cdot)$ & 8.17 & $8 L$ & $\therefore$ & 7.34 & S1 & 9 & 8.05 & 81 & 9 \\
\hline 7 & Kecemalban petairan (ni) & 2 & Si & 3 & $\infty$ & si & 3 & $\infty$ & S1 & 3 \\
\hline s. & P'uurupar lehan pantai & $\begin{array}{l}\text { Libun lerbulat. } \\
\text { Pchon kelapa }\end{array}$ & 81 & 3 & $\begin{array}{l}\text { Lahay } \\
\text { terhela } \\
\text { Poboe } \\
\text { hrlialial }\end{array}$ & S1 & j & $\begin{array}{l}\text { Lebar } \\
\text { tarmika. } \\
\text { Pohen } \\
k+1 \text { lai }\end{array}$ & 81 & 3 \\
\hline 9. & Bielaberbataya & Tidiak atia & SL & 3 & Tidals alit & $\$ 1$ & 3 & $\begin{array}{l}\text { Tidik } \\
\text { ads }\end{array}$ & SI & 3 \\
\hline 10 & $\begin{array}{l}\text { Ketcrs cdiann air tawar } \\
\text { (hin) }\end{array}$ & $<05$ & Si & 3 & $<05$ & $\$ 1$ & 1 & e $0 \overline{5}$ & $\$ 1$ & $\hat{3}$ \\
\hline & Tntal & & S! & 71 & & S1 & 71 & & $\$ 1$ & 75 \\
\hline
\end{tabular}

Hasil dari nilai Indeks Kesesuaian Wisata Pantai Nglambor saat Pasang (Pagi Hari) disajikan dalam Tabel 5 di bawah ini : 
Tabel 5. Indeks Kesesuaian Wisata Pantai Nglambor saat Pasang (Pagi Hari)

\begin{tabular}{|c|c|c|c|c|c|c|c|c|c|c|}
\hline No. & Variabd & $\begin{array}{c}\text { Hisil } \\
\text { Stasun } 1\end{array}$ & Kaiegen & $\begin{array}{c}\text { Skm } \\
\text { Kateger: }\end{array}$ & $\begin{array}{c}\text { Rasi } \\
\text { Stasiun } 11\end{array}$ & Rercgori & $\begin{array}{c}\text { Shar } \\
\text { Karegori }\end{array}$ & $\begin{array}{c}\text { II ลลi์ } \\
\text { Stasiun } \\
\text { III }\end{array}$ & Tategon & $\begin{array}{l}\text { Shce } \\
\text { biatcgori }\end{array}$ \\
\hline 1. & $\begin{array}{l}\text { Kodatamen perairan } \\
\text { (iii) }\end{array}$ & 0.60 & \$1 & 15 & 1.0 & \$1 & 15 & 1.10 & S1 & 15 \\
\hline 2. & lipe pantai & $\begin{array}{l}\text { Pasiy putih. } \\
\text { Sedikit caranp }\end{array}$ & 32 & 10 & $\begin{array}{c}\text { Pusi putit. } \\
\text { Sedikit } \\
\text { kir } n \text {. }\end{array}$ & 52 & 10 & $\begin{array}{l}\text { P'asir } \\
\text { prith }\end{array}$ & $\mathrm{si}$ & 12 \\
\hline 3. & I thar pantal (m) & 56 & S3 & 5 & 105 & $\$ 2$ & 10 & 100 & $\$ 2$ & 101. \\
\hline 4 & Mairsial alasat peraitan & $\begin{array}{l}\text { Katang } \\
\text { bespaze }\end{array}$ & S? & G & $\begin{array}{l}\text { Katann } \\
\text { bespasis }\end{array}$ & 82 & 6 & $\begin{array}{l}\text { Katans } \\
\text { bespasis }\end{array}$ & $\mathrm{s} 2$ & 6 \\
\hline 5. & Krertian atit (n) & 014 & S1 & 9 & 014 & $\$ L$ & 9 & 010 & 61 & 9 \\
\hline 6. & Kericingan pantain & 8.33 & $\$ 1$ & 9 & y.3. & Si & 9 & S.10 & $\$ 1$ & 9 \\
\hline 7. & 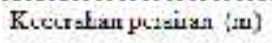 & it & 81 & 3 & 4 & 81 & 3 & u: & 81 & 3 \\
\hline 8 & Pemugan 1ahan pantai & $\begin{array}{l}\text { Lahan terbuka, } \\
\text { Puthun kel pii }\end{array}$ & Si & $?$ & $\begin{array}{l}\text { T.ahm } \\
\text { Letwaky } \\
\text { Polos } \\
\text { kclepa. }\end{array}$ & \&i & 3 & $\begin{array}{l}\text { Tahan } \\
\text { tabuk. } \\
\text { Polues } \\
\text { belspa. }\end{array}$ & s1 & 3 \\
\hline y. & Eiota berobays & Lidak ad̉a & 81 & 3 & 'Lidek ada & $\$ 1$ & 3 & $\begin{array}{c}\text { Tulsk } \\
\text { ada }\end{array}$ & 81 & 3 \\
\hline \multirow[t]{2}{*}{10} & $\begin{array}{l}\text { Katersed } \\
\text { (kon) }\end{array}$ & $\therefore 05$ & S1 & 3 & $\therefore 05$ & $\$ 1$ & 3 & $<05$ & Si & 3 \\
\hline & Tutal & & $\mathrm{S2}$ & 66 & & 81 & 71 & & S1 & 76 \\
\hline
\end{tabular}

Hasil dari Kategori Kesesuaian Wisata Pantai Nglambor disajikan dalam Tabel 6 di bawah ini :

Tabel 6. Kategori Kesesuaian Wisata Pantai Nglambor

\begin{tabular}{clllc}
\hline Stasiun & Waktu Sampling & Ni & IKW & Kategori \\
\hline Stasiun I & Saat surut (Sore) & 71 & $84.52 \%$ & S1 \\
& Saat pasang (pagi) & 66 & $78.57 \%$ & S2 \\
\multirow{2}{*}{ Stasiun II } & Saat surut (sore) & 71 & $84.52 \%$ & S1 \\
& Saat pasang (pagi) & 71 & $84.52 \%$ & S1 \\
\multirow{2}{*}{ Stasiun III } & Saat surut (sore) & 76 & $90.48 \%$ & S1 \\
& Saat pasang (pagi) & 76 & $90.48 \%$ & S1 \\
\hline
\end{tabular}

Berdasarkan hasil pengukuran, kedalaman perairan untuk stasiun I saat surut dan pasang berkisar antara 0,6$0,75 \mathrm{~m}$, stasiun II saat surut dan pasang antara 1,0-1,05 m, dan stasiun III saat surut dan pasang bernilai sebesar 1,1 m. Pada semua stasiun, sore maupun pagi hari termasuk dalam kategori S1 atau Sangat Sesuai (Highly Suitable) yang berarti bahwa dengan kisaran kedalaman perairan dengan nilai tersebut bisa digunakan untuk kegiatan wisata air atau wisata pantai di tiap stasiunnya. Menurut Yulianda (2007), suatu kawasan wisata pantai dapat dikatakan sangat sesuai jika memiliki kedalaman berkisar antara 0-3 m. Sebagaimana menurut Nugraha et al., (2013), mengemukakan kedalaman yang paling baik untuk kegiatan berenang berada pada kisaran 0-5 m.

Tipe pantai pada stasiun I dan stasiun II saat surut dan pasang adalah pasir putih dengan sedikit karang dimana kondisi ini termasuk dalam kategori S2 atau Sesuai. Sedangkan pada stasiun III saat surut dan pasang bertipe pasir putih yang masuk dalam kategori S1 atau Sangat Sesuai. Menurut Wunani (2014), bahwa tipe pantai yang sangat sesuai untuk kegiatan wisata pantai berdasarkan jenis substrat/sedimen adalah pantai berpasir.

Salah satu variabel yang membuat pengunjung ingin berwisata ke Pantai Nglambor adalah tipe pantainya. Pada bibir pantai memiliki pasir putih dengan sedikit pecahan karang dan pada bawah air memiliki keunikan yaitu pecahan batu karst serta karang. Bagi pengunjung, pemandangan bawah air merupakan pengalaman baru yang unik karena tidak ditemukan di pantai lainnya, Pantai Nglambor menawarkan pemandangan bawah air dengan pemandangan batu karst dan karang dengan ombak yang sedikit kuat. Pengunjung mendapatkan sensasi yang berbeda jika melakukan rekreasi snorkeling di pantai ini. Karakteristik bentuk pantai berbeda-beda antara tempat yang satu dengan tempat lainnya. Ada pantai berpasir yang datar dan landai, berbatu dan terjal, serta berlumpur. Keadaan topografi dan geologi wilayah pesisir mempengaruhi perbedaan bentuk pantai. Pantai Nglambor memiliki karakter pantai berpasir dan berbatu. Menurut Nybakken (1992), umumnya pantai berpasir terdapat di seluruh dunia dan lebih dikenal dari pada pantai berbatu. Hal ini disebabkan pantai berpasir merupakan tempat yang dipilih untuk melakukan berbagai aktivitas rekreasi. Sedangkan menurut Islami (2003), peruntukan pantai dengan substrat pasir hitam adalah boating, sedangkan pantai berpasir putih lebih bervariasi, seperti boating, selancar, renang, snorkeling dan diving.

Pengukuran lebar pantai untuk stasiun I saat surut dan pasang berkisar antara 6,6-12,7 m, stasiun II saat surut dan pasang sebesar 10,5-13,8 m, dan stasiun III saat surut dan pasang bernilai sebesar $10 \mathrm{~m}$. Pada semua stasiun,

\footnotetext{
${ }^{\circ}$ Copyright by Management of Aquatic Resources (MAQUARES)
} 
sore maupun pagi hari termasuk dalam kategori S2 atau Sesuai (Suitable). Menurut Rahmawati (2009) dalam Wunani (2014), lebar pantai berkaitan dengan lahan pantai yang dapat dimanfaatkan untuk berbagai aktivitas wisata pantai. Lebar pantai sangat mempengaruhi aktivitas yang dilakukan para wisatawan, semakin lebar suatu pantai maka semakin baik untuk wisatawan dalam melakukan aktivitasnya, namun semakin kecil lebar pantai yang dimiliki oleh suatu tempat wisata maka pengunjung merasa tidak nyaman untuk melakukan aktivitas.

Material dasar perairan pada semua stasiun adalah karang berpasir dengan pasir yang lebih dominan daripada jenis karangnya. Selain itu, terdapat batuan sejenis karst (batu gamping) yang menghiasi bawah air. Batuan ini yang dijadikan objek maupun atraksi untuk dilihat para wisatawan. Bagi wisatawan, pemandangan ini dinilai unik karena jarang ditemukan di tempat lainnya.

Pengukuran kecepatan arus untuk stasiun I saat surut dan pasang berkisar antara $0,10-0,14 \mathrm{~m} / \mathrm{s}$, stasiun II saat surut dan pasang sebesar $0,14-0,17 \mathrm{~m} / \mathrm{s}$, dan stasiun III saat surut dan pasang bernilai sebesar $0,10-0,14 \mathrm{~m} / \mathrm{s}$. Menurut Yulianda (2007), dapat dikatakan bahwa hasil pengukuran arus tersebut sangat sesuai untuk aktivitas berenang karena memiliki kecepatan arus kategori S1 atau Sangat Sesuai dengan kecepatan antara 0 - 0,17.

Pengukuran kemiringan pantai pada stasiun I saat surut dan pasang sebesar $8,17^{\circ}-8,53^{\circ}$, stasiun II sore dan pagi hari sebesar $7,94^{\circ}-8,31^{\circ}$, dan stasiun III saat surut dan pasang bernilai sebesar $8,05^{\circ}$. Pada semua stasiun, kemiringan pantai sore maupun pagi hari termasuk dalam kategori S1 atau Sangat Sesuai (Highly Suitable) karena bernilai $\leq 10^{\circ}$. Menurut Safina (2014), kemiringan pantai yang kurang dari $10^{\circ}$ dianggap paling sesuai untuk wisata pantai, sementara kemiringan pantai yang lebih dari $45^{\circ}$ dianggap tidak sesuai untuk wisata pantai karena dianggap curam.

Pengukuran kecerahan perairan pada semua saat surut dan pasang adalah sampai mengenai dasar perairan sehingga rerata kecerahan memiliki nilai yang sama dengan kedalaman. Hal ini menunjukkan bahwa kondisi perairan di tiap stasiun tidak keruh dan dasar perairannya dapat terlihat. Kecerahan perairan tiap stasiun termasuk dalam kategori S1 atau Sangat Sesuai, sebagaimana yang dikemukan oleh Yulianda (2007), bahwa suatu parameter kecerahan perairan untuk kategori wisata pantai seharusnya memiliki kecerahan perairan yaitu lebih dari $10 \mathrm{~m}$.

Penutupan lahan di Pantai Nglambor adalah lahan terbuka, area persawahan, dan perbukitan. Terdapat pemukiman penduduk kurang lebih berjarak $2 \mathrm{~km}$ dari Pantai Nglambor. Untuk biota berbahaya tidak ada di tiap stasiun Pantai Nglambor sehingga aman digunakan untuk kegiatan wisata pantai, berenang, dan snorkeling. Kriteria penutupan lahan pantai dan biota berbahaya pada tiap stasiun termasuk dalam kategori S1 atau Sangat Sesuai (Highly Suitable).

Pantai Nglambor dapat dikatakan sangat sesuai karena memiliki jarak untuk ketersediaan air tawar hanya sebesar 0,2 km atau $200 \mathrm{~m}$. Ketersediaan air tawar terdapat pada penegelola fasilitas kamar mandi yang jaraknya dekat dengan pantai. Menurut Dahuri (2003), bahwa sumber air tawar mutlak diperlukan, terutama untuk kelangsungan hidup penduduk (manusia) dan menunjang pengembangan potensi kepariwisataan di wilayah pulaupulau kecil. Jika dihubungkan dengan kegiatan wisata pantai maka hal ini erat kaitannya karena sebagai penunjang bagi wisatawan dalam melakukan kegiatan berenang. Sebagaiamana menurut Yulianda (2007), pada matriks kesesuaian lahan kategori wisata pantai bahwa suatu wisata pantai dapat dikatakan sangat sesuai jika memiliki jarak ketersediaan air tawar $<0,5 \mathrm{~km}$.

Menurut Supriharyono (2000), berbanding lurus dengan meningkatnya wisatawan yang datang ke pantai, maka beberapa kebutuhan pendukung dan keberadaan fasilitas wisata juga meningkat di daerah tersebut. Beberapa kebutuhan dan fasilitas tersebut adalah penginapan, air bersih, dan makanan.

Pengambilan data primer penelitian dilakukan pada tiga stasiun yang berbeda dilakukan pada waktu surut (sore) dan pasang (pagi). Pengambilan data pada variabel-variabel yang sudah disebutkan didapatkan hasil yang berbeda. Berdasarkan hasil pengukuran semua stasiun didapatkan nilai Indeks Kesesuaian Wisata (IKW) pada Stasiun I dan II saat surut (sore) didapatkan nilai masing-masing sebesar 84.52\%. Variabel-variabel yang termasuk dalam kategori S1 adalah kedalaman perairan, kecepatan arus, kemiringan pantai, kecerahan perairan, penutupan lahan pantai, biota berbahaya, dan ketersediaan air tawar dimana nilainya membuat persentase nilai IKW menjadi tinggi. Sedangkan variabel tipe pantai, lebar pantai, dan material dasar perairan termasuk kategori S2, namun variabel-variabel tersebut tidak membuat nilai IKW terlalu rendah. Variabel-variabel ini diyakini tidak berpengaruh secara nyata untuk kebutuhan wisata. Stasiun III saat surut (sore) didapatkan nilai sebesar $90.48 \%$. Menurut Yulianda (2007), nilai Indeks Kesesuaian Wisata (IKW) yang berkisar antara 83-100\% termasuk dalam kategori S1. Kategori S1 memiliki arti kesesuaian lahan wisata pantai Sangat Sesuai (Highly Suitable), pada kategori ini tidak memiliki faktor pembatas yang berat untuk suatu penggunaan tertentu secara lestari atau hanya memiliki pembatas yang kurang berarti dan tidak berpengaruh secara nyata.

Kegiatan ekowisata di Pantai Nglambor juga dilakukan pada saat pasang (pagi). Wisatawan banyak yang datang untuk menikmati sunrise dan juga pemandangan alam dari pantai Selatan tersebut. Pengambilan data juga dilakukan pada pagi hari, ini berfungsi sebagai pembanding apakah ada perbedaan yang mencolok untuk nilai Indeks Kesesuaian Wisata (IKW) beserta kategorinya di sore hari maupun pagi hari. Stasiun I saat pasang (pagi) didapatkan nilai sebesar $78.57 \%$ yang termasuk dalam kategori S2. Nilai kedalaman perairan yang rendah menjadikan nilai IKW pada stasiun ini menurun. Menurut Yulianda (2007), kategori S2 memiliki arti Sesuai (Suitable), kategori ini memiliki faktor pembatas yang agak berat untuk suatu penggunaan tertentu secara lestari.

Co Copyright by Management of Aquatic Resources (MAQUARES) 
Faktor pembatas tersebut akan mempengaruhi kepuasan dalam kegiatan wisata dan keuntungan yang diperoleh serta meningkatkan masukan perlakuan yang diperlukan untuk mengusahakan kegiatan wisata tersebut. Stasiun II saat pasang (pagi) didapatkan nilai sebesar $84.52 \%$, Stasiun III saat pasang (pagi) didapatkan nilai sebesar $90.48 \%$. Stasiun II dan III termasuk dalam kategori S1 atau Sangat Sesuai (Highly Suitable), pada kategori ini tidak memiliki faktor pembatas yang berat untuk suatu penggunaan tertentu secara lestari atau hanya memiliki pembatas yang kurang berarti dan tidak berpengaruh secara nyata.

\section{KESIMPULAN}

Kesimpulan yang dapar diambil dari penelitian adalah sebagai berikut:

1. Potensi wisata Pantai Nglambor ada pada kondisi fisik pantai yang unik dan indah, serta jenis kegiatan atau daya tarik wisatanya yaitu rekreasi berenang dan rekreasi snorkeling.

Perkembangan wisata Pantai Nglambor dalam satu tahun sudah menjadi tujuan utama bagi pengunjung dan nilai untuk kepuasan serta keinginan untuk kembali berkunjung dari pengunjung adalah 95.1\%;

2. Indeks Kesesuaian Wisata (IKW) untuk Pantai Nglambor pada semua Stasiun saat surut (sore) dan dan saat pasang (pagi) adalah S1 atau Sangat Sesuai (Highly Suitable) dengan kisaran nilai sebesar 84.52\% hingga 90.48\% kecuali pada Stasiun I saat pasang (pagi) termasuk kategori S2 atau Sesuai (Suitable) dengan nilai sebesar $78.57 \%$.

\section{UCAPAN TERIMA KASIH}

Penulis mengucapkan terima kasih kepada Prof. Dr. Ir. Sahala Hutabarat, M.Sc, Dr. Ir. Suryanti, M.Pi, dan Dr. Ir. Bambang Sulardiono, M.Si yang telah memberikan kritik dan saran untuk perbaikan penelitian ini.

\section{DAFTAR PUSTAKA}

Dahuri, R. 2003. Keanekaragaman Hayati Laut: Aset Pembangunan Berkelanjutan Indonesia. Gramedia Pustaka Utama, Jakarta.

Emzir. 2012. Metodologi Penelitian Pendidikan: Kuantitatif dan Kualitatif. Rajawali Pers, Jakarta.

Fandeli, C. 2000. Pengertian dan Konsep Dasar Pariwisata. Penerbit: Fakultas Kehutanan Universitas Gadjah Mada, Yogyakarta.

Islami, N. A. 2003. Pengelolaan Pariwisata Pesisir (Studi Kasus Taman Rekreasi Pantai Kartini Rembang, Jawa Tengah). [Tesis]. Departemen Manajemen Sumberdaya Perairan, Fakultas Perikanan dan Ilmu Kelautan. Institut Pertanian Bogor, Bogor.

Juliana. 2013. Kesesuaian dan Daya Dukung Wisata Bahari di Perairan Bandengan Kabupaten Jepara Jawa Tengah. Jurnal Perikanan dan Ilmu Kelautan. Volume IX, Nomor 1.

Koswara, I.H. 2005. Karakteristik dan Potensi Wisata Agro Jawa Barat. Angkasa, Bandung, 27 hlm.

Lestari, L.H. 2013. Komparasi Karakteristik Pantai Peneluran Penyu (Kasus Pantai Pengumbahan dan Sindang Kerta Jawa Barat). [Tesis]. Fakultas Perikanan dan Ilmu Kelautan, Universitas Padjajaran, Bandung.

Nybakken, J. W. 1992. Biologi Laut : Suatu Pendekatan Ekologis. H. M. Eidman, D. G. Bengen, Malikusworo H., dan Sukristijono S., Penerjemah. Terjemahan dari: Marine Biology: An Ecological Approach. PT Gramedia, Jakarta.

Safina, E., P. Patana, dan A. Muhtadi. 2014. Analisis Potensi dan Daya Dukung Kawasan Wisata Pantai Mutiara 88 Kecamatan Pantai Cermin Kabupaten Serdang Bedagai. Program Studi Manajemen Sumberdaya Perairan, Fakultas Pertanian, Universitas Sumatera Utara, Medan.

Sugiyono. 2009. Metode Penelitian Bisnis (Pendekatan Kuantitatif, Kualitatif, dan R\&D). Alfabeta, Bandung.

Sunarto. 1991. Geomorfologi Pantai. Kursus Singkat Pengelolaan dan Perencanaan Bangunan Pantai. Pusat Antar Universitas Ilmu Teknik UGM, Yogyakarta.

Supriharyono. 2000. Pelestarian dan Pengelolaan Sumber Daya Alam di Wilayah Pesisir Tropis, Gramedia Pustaka Utama, Jakarta.

Wunani, D., S. Nursinar, dan F. Kasim. 2014. Kesesuaian Lahan dan Daya Dukung Kawasan Wisata Pantai Botutonuo Kecamatan Kabila Bone Kabupaten Bone Bolango. Jurnal Ilmiah Perikanan dan Kelautan, Vol. 2, No.1, hlm 18-22, Jurusan Teknologi Perikanan, Fakultas Ilmu Pertanian, Universitas Negeri Gorontalo, Gorontalo.

Yoety, O.A. 1996. Pemasaran Pariwisata. Angkasa, Bandung.

Yulianda, F. 2007a. Ekowisata Bahari Sebagai Alternatif Pemanfaatan Sumberdaya Pesisir Berbasis Konservasi. [Makalah]. Departemen Manajemen Sumberdaya Perairan, Fakultas Perikanan dan Ilmu Kelautan, Institut Pertanian Bogor, Bogor.

2007b. Ekowisata Bahari Sebagai Alternatif Pemanfaatan Sumberdaya Pesisir Berbasis Konservasi Dalam: Seminar Sains 21 Februari 2007. Departemen Manajemen Sumberdaya Perairan, Institut Pertanian Bogor, Bogor.

Yustishar. M. 2012. Tinjauan Parameter Fisik Pantai Mangkang Kulon Untuk Kesesuaian Pariwisata Pantai di Kota Semarang. Journal of Marine Research 1 (2) : 8-16. 